\title{
Kadın Jeokritiğinin Erkek Otokritiği Üzerine Etkisi: Assia Djebar Medine’den Uzaklarda - Nedim Gürsel Allah'zn Kızlarz ${ }^{1}$
}

\section{Cansu GÜMÜŞTAŞ ŞEN²}

\begin{abstract}
Özet
Zaman ve mekân sorunsalı uzun seneler boyunca tek odaklı olarak irdelenirken, 20. yy'da yaşanan sosyo-ekonomik ve politik gelişmelerin etkisiyle yeni bir boyut kazanmıştır. Söz konusu olan, bu yeni çok disiplinli anlamlandırmayı bir nebze aydınlatabilmek için, bu çalışmada her ikisi de Frankofon ve Akdenizli yazar olan Assia Djebar'ın "Medine'den Uzaklarda” ve Nedim Gürsel’in “Allah'ın Kızları” adlı yapıtına yer verildi. Nedim Gürsel, eserinde Cahiliye ve İslamiyet’in doğduğu dönemi yeniden canlandırırken, Assia Djebar, Hz. Muhammed'in ölümü ile başlayan dört halife dönemini yeniden kurgular. Ve eserlerinde, her ikisi de birbirini bütünleyen zaman dilimlerinde, aynı topraklara, İslam coğrafyasına (Mekke ve Medine'ye) zihinsel yolculuk yaparlar. Burada, daha önceden var olan ve her daim var olacak unsurlara, kimi yerlerde örtüşen kimi yerlerde ayrışan kadın ve erkek bakış açısı getirmişlerdir. Birçok kere anlamlandırılmış bu zaman ve mekânlara, özyaşamöykülerinden yola çıarak Frankofon, Akdenizli, çift kültürlü, sömürgeciliği yaşamış yazarlar olarak yeni anlamlar yüklemişlerdir. Tabi bu yaratma süreci, sosyokültürel alanda genel olarak kabul görmüş İslam paradigmasından bağımsız olarak düşünülmemelidir. Bu yerleşik paradigma ile yeni paradigmalar arasındaki gelgitler ise; bize metinlerarasılık (intertekstüalite) kavramını çağrıştırmaktadır. Daha önce kaleme alınmış olan, İslam coğrafyasına eleştirel yaklaşım (jeokritik) getiren "Medine'den Uzaklarda" eseri, daha sonra kaleme alınan Nedim Gürsel'in "Allah'ın Kızları" adlı yazınını, konu ve stil bakımından derinden etkilemiş fakat onun yazınında ve hayal gücünde jeokritik özeleştiriye (otokritik) dönüşmüştür.
\end{abstract}

Anahtar Kelimeler: Assia Djebar "Medine'den Uzaklarda", Nedim Gürsel "Allah’ın Kızları", zaman ve mekân sorunsalı, jeoktritik.

\section{The Impact Of Female Geocriticism On Male Autocriticism: Assia Djebar's Far From Mediyna - Nedim Gürsel's The Daughters Of Allah}

\begin{abstract}
While the problematics of time and space has been revised through a biased perspective for many years, it has gained a new dimension under the influence of socio-economic and political developments in the $20^{\text {th }}$ century. In the present study, two novels Far From Medina and The Daughters of Allah by two Mediterranean, Francophone writers, Assia Djebar and Nedim Gürsel respectively, have been studied in order to shed light on to this new and multidisciplinary interpretation. As Nedim Gürsel depicts the Djahilia period and the advent of Islam in his work, Assia Djebar fictionalizes the period of four caliphs after the death of Muhammad. In the novels, both plunge into an intellectual journey to the same land, the Islam geography (Mecca and Medina) in close and complementary time periods. There, they bring about intermittently convergent and sometimes divergent male and female perspectives on the pre-existing and eternal social elements. Based on their own autobiographies, these two Francophone, Mediterranean, and bicultural authors that have experienced colonialism have inflicted new essence to these perpetual and almost dimensionless time periods and localities. Obviously, this process of creation
\end{abstract}

$1 \quad \mathrm{Bu}$ makale XI. Ulusal Frankofoni Kongresi kapsamında 12 Mayı 2015 tarihinde Ylddz Teknik Üniversitesi’nde sunulan metnin genişletilmiş halidir.

2 Okt., Yeditepe Üniversitesi İktisadi ve İdari Bilimler Fakültesi (Fransızca) Fransızca Siyaset Bilimi ve Uluslararası İlişkiler, cansugumustassen@hotmail.com 
Kadın Jeokritiğinin Erkek Otokritiği Üzerine Etkisi: Assia Djebar Medine’den Uzaklarda - Nedim Gürsel Allah'in Kızları / C. Gümüştaş-Şen (70-77. s.)

should not be considered independent of the Islamic paradigm generally accepted in the socio-cultural field. The fluctuations between the well-settled paradigm and the new ones evoke the concept of intertextuality. As an earlier work, Far From Medina criticizing Islamic geography (geocriticism) has deeply influenced Nedim Gürsel's novel The Daughters of Allah in terms of subject and style, and additionally it has been transformed into geocritic autocriticism within the latter's literature and imagination.

Keywords: Assia Djebar Far From Medina, Nedim Gürsel The Daugthers of Allah, the problem of space and time, geocriticism.

\section{Giriş}

Frankofon, Akdenizli, çift kültürlü, sömürgeciliği yaşamış yazarlar olan Assia Djebar ve Nedim Gürsel, "Medine'den Uzaklarda” ve "Allah'ın Kızları” adlı eserlerinde birçok kere farklı şekillerde anlamlandırılmış zaman ve mekâna, kendi özyaşamöykülerinden yola çıkarak yeni anlamlar yüklemişlerdir. Tabi bu yaratma süreci, hem kendi hayatlarında birebir etkili olan İslam kültüründen, hem de sosyo-kültürel alanda genel olarak kabul görmüş İslam paradigmasından bağımsız olarak düşünülmemelidir. Bunun yanı sıra, bu bakış açısının romanlarda ele alınan tarihi olgular ve onların öz yaşam öykülerinde yadsınamaz bir etkisi olmuştur.

$\mathrm{Bu}$ yerleşik paradigma ile onların eserlerinde yarattığı yeni paradigmalar arasındaki gelgitler bize metinlerarasılık (intertekstüalite) kavramını çă̆rıştırmaktadır. Bu süreç, sorgulama, eleştiri ve tartışma alt stratejilerini de bünyesinde barındırmaktadır. Zira Assia Djebar, romanında ünlü İslam tarihçisi Taberi'yi hem referans hem de muhatap alırken, Nedim Gürsel ise; hem Kuran'ı Kerim'deki surelere göndermeler yapar hem de Taberi, İbni Hişam gibi tarihçilerin yazınlarından esinlenir.

\section{Eserlerde Zaman ve Mekân Olgusu}

Nedim Gürsel, ağırlıklı olarak Cahiliye ve İslamiyet’in doğduğu dönemi ele alırken, Assia Djebar, Hz. Muhammed’in ölümü ile başlayan dört halife dönemini yeniden kurgular. Ve eserlerinde, her ikisi de birbirini bütünleyen zaman dilimlerinde, aynı topraklara, İslam coğrafyasına (Mekke ve Medine'ye) zihinsel yolculuk yaparlar. Elbette, bu geçmişe yapılan soyut yolculuğun her ikisi için de, bulunduğumuz çağda somut karşılıkları mevcuttur. Çünkü her iki yazar da öz yaşam öyküsünü, yani bireysel tarihi, toplumsal tarihin yansıması olarak görür. Böylelikle, daha önceden var olan ve her daim var olacak unsurlara bir diğer bakımdan paradigmalara, kimi yerlerde örtüşen kimi yerlerde ayrışan kadın ve erkek bakış açısı getirmişlerdir.

\subsection{Allah'ın Kızlarında zaman ve mekânsal kopuşun getirdiği “ben”lik arayışı}

S. Seza Yılancıŏlu'nun da Göçebeliğin Büyüsü adlı kitabında "Nedim Gürsel’in yapıtlarında dini karakterler" adlı makalesinde ele aldığı gibi Nedim Gürsel, eserinde de yer verdiği Cumhuriyet’in ilanı ile zaman ve mekânsal bir kopuş yaşamıştır.

“Bir İslam İmparatorluğu'nun laik bir devlete dönüștüğü sancllı süreç, Türkler 'de zaman ve mekân algısında bir kopukluk yaratmıştır. (...) Böylelikle, tarihi ve kültürel kopukluklar, çağdaşları gibi Nedim Gürsel'i de doğduğu ülkenin zaman ve uzam sürecinde oluşan kültürel farklılıkları bugün itibariyle irdelemeye sürüklemiştir” (Yılancıŏ̆lu, 2014, s 57-58).

Varlığın kanıtı olan zaman ve mekânsal hâkimiyet, hem kendi (öz) tarihi hem de ülkesinin tarihi için ellerinden kayıp gitmiştir. Bu nedenle, kendini toplumsal tarihin bir yansıması 
olarak gören Nedim Gürsel, eserinde hem kendi hayatı için hem de Türkiye tarihi için zaman ve mekânı yeniden anlamlandırmaya çalışmıştır. Zira yazarın yaşadı̆̆ zorunlu göç, çift kültürlülük, çift dillilik onun zaman ve uzamsal işlevini yerine getirmesine, yani var olmaya devam etmesine engel olmuştur. Eserinde geçmişe yaptığı zihinsel yolculukla, hem kendi hayatı için hem de Türkiye için geçmişteki sorunları ele alarak hem ülkesi hem de kendisi için zaman ve uzamsal varlığın hâkimiyetini tekrar ele alıp geleceğe ilerlemenin yolunu aramaktadır.

\subsection{Medine'den Uzaklarda'da zaman ve mekânsal kopuşun getirdiği "kadın" kimliği arayışı}

Assia Djebar, eserinde Cezayir tarihinden yola çıararak, sömürülen Cezayir ve Cezayir kadınlarını, Müslüman kadınları ele almıştır. Eserinde, Hz. Muhammed’in ölümü ile başlayan dört halife dönemini, Cezayir’in bağımsızlık mücadelesi, kadınların kamusal alanda söz sahibi olması ve özgürleşmesi ve kendi hayatı arasındaki benzerlikleri ortaya koymak için ideal dönem olarak nitelendirir. Ve bu unsurlara zaman aralığını sabitleyip zamanı yavaşlatıp, mekânı detaylandırarak coğrafi eleştirel (jeokritik) bakış açısı getirir.

"Jeokritik, mekânın içiyle-dışıyla, genel algısıyla-kurgusuyla, gerçeğiyle-hayaliyle, çok yönlü bir bakış açısı benimser. Bu bakış açısı, mekânın zaman üzerindeki dolasıyla da coğrafyanın tarih üzerindeki zaferine dönüşür. Assia Djebar, dört halife döneminin Medine'sini, o dönemin gerçek tarihi olgularıyla değil de, bugüne kadar göz ardı edilen kadın sesi ve eylemleriyle okuyucuya yansitı”" (Gümüştaş Şen, 2014).

\section{Geçmiş ve Şimdiki Zaman Arasındaki Gelgitler: "Jeokritik ve Otokritik”}

\subsection{Assia Djebar ve Jeokritik}

Jeokritik, mekânı detaylandırarak, aslında zamanın betimlenebileceğini savunur. Coğrafi eleştirel bakış açısı olmaksızın, Assia Djebar'ın "Medine'den Uzaklarda” adlı eseri, dört halife dönemini ve özellikle o dönemdeki kadınları ele alan bir İslami tiyatrodur. Fakat romanın derinliklerinde, Cezayir'in bağımsızlık mücadelesi, sömürgecilikle mücadele yatar. O dönemde, halifelerin seçimle yönetime gelmesi, ilk demokratikleşme hareketi olması itibariyle Cezayir'in 1990'lı yıllarını yansitır.

\begin{tabular}{|c|c|c|}
\hline Hz. Muhammed & Dört Halife & Kadın'ın \\
\hline Dönemi & Dönemi & Özqürlesmesi \\
\hline$\downarrow$ & $\downarrow$ & $\downarrow$ \\
\hline $\begin{array}{c}\text { FLN } \\
\text { Kurtuluş Cephesi) }\end{array}$ & $\begin{array}{c}\text { FIS } \\
\text { (İslami Selamet Cephesi) }\end{array}$ & Darbe (Ulusal \\
\hline
\end{tabular}

Şekil 1: Assia Djebar’ın yazınında üçlü zamansal eşleşme

Bağımsızlık Savaşı'ndan sonra, 1980'li yıllara kadar ülkeyi ulusal kurtuluş cephesi (FLN) yönetir. 8o'li yılların sonuna doğru, ülkede çok partili döneme geçişe, demokratikleşmeye 
Kadın Jeokritiğinin Erkek Otokritiği Üzerine Etkisi: Assia Djebar Medine’den Uzaklarda - Nedim Gürsel Allah’n Kızları / C. Gümüştaş-Şen (70-77. s.)

yönelik girişimler baş gösterir. 1989 yılında, referandumla kabul edilen yeni anayasayla birlikte ülke çok partili hayata geçer ve 1990 yılındaki ilk seçimleri İslami selamet cephesi (FIS) açık ara farkla kazanır. Fakat bu çok uzun sürmez, 1992 yılında gerçekleştirilen darbe ile demokratikleşme hareketi çok uzun bir süre askıya alınır.

Sömürgecilikle mücadele, Assia Djebar’ın yazınında çift yönlü olarak yer bulur: Fransa'nın Cezayir üzerindeki egemenliği, Ataerkil düzenin getirmiş olduğu erkeğin kadın üzerindeki hâkimiyeti. Zira yazar, bu iki egemenliği de sömürü olarak adlandırır. Dolayısıyla; roman, bu öğelerin tümünü bünyesinde barındırması sebebiyle sömürgecinin diliyle sömürüye karşı mücadele eden çok sesli (polifonik) bir romana dönüşür. Uzak geçmişte ve yakın geçmişte darbe girişimiyle son bulan demokratikleşme hareketi için tarihi sayfaları aralayarak bir çıkış yolu arar.

\subsection{Jeokritik ve Nedim Gürsel}

Nedim Gürsel ise; eserinde Cahiliye dönemi, İslamiyet'in kabul edildiği dönem, Osmanlı İmparatorluğu'nun son dönemi, Cumhuriyet'in ilk yılları ve Türkiye'nin 1950'li yılları olmak üzere birçok zamana yer vermiştir. Bu dönemler, Manisa, İstanbul, Mekke aracılığıyla okuyucuya yansıtılır. İlk bakışta, bunlar birbiriyle bağdaşmayan unsurlar olarak gözükse de, yazarın kurgusunda kendi hayat hikâyesi ile İslamiyet ve Türkiye tarihi arasında yaptığı ortak zaman ve uzamsal seçimler, bireysel ve toplumsal tarihi birbirini bütünler hale getirir.

Cahiliye dönemi, annesi ve iki teyzesi olmak üzere kadınların arasında geçen çocukluğuna, İslamiyet'in kabul edildiği dönem, iyi birer Müslüman olan dedesinin ve anneannesinin yanında geçen çocukluğunun ikinci bölümüne, Osmanlı İmparatorluğu'nun son dönemi, trafik kazasında babasının ölümüyle birlikte hem babasından hem de Fransa'ya giden annesinden ayrılışına, Cumhuriyet'in ilk yılları, Galatasaray Lisesi'nde batı dünyasıyla ilk karşılaşmasına ve Türkiye’nin 1950'li yılları ise; Fransa’ya yaptığı zorunlu göçe karşılık gelir.

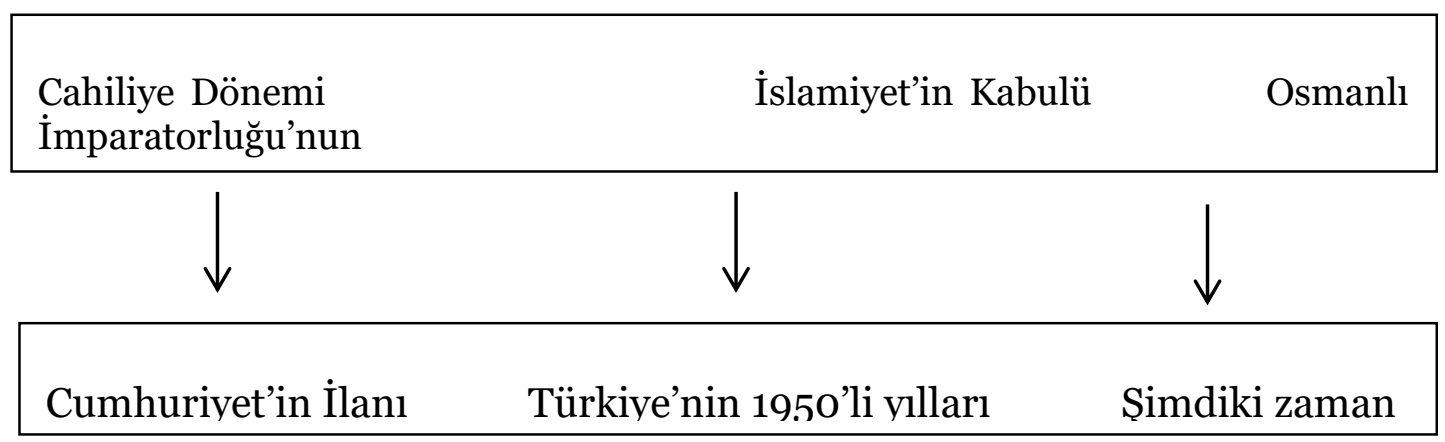

Şekil 2: Nedim Gürsel’in yazınında üçlü zamansal eşleşme

Zira bu zaman ve uzamsal seçimler başta öz yaşam öyküsü olmak üzere her iki tarih için de temel kriz anlarından oluşur. Yazar tarafindan seçilen temel kriz anları, hem ülkesinin doğu ve batı dünyası arasındaki ikilemini, çok kültürlülüğünü, dış etkiler yüzünden yaşadığı sömürülmüsşlügünü gözler önüne sererken, amacı ülkesinin tam olarak zaman ve mekânsal hâkimiyeti ele alamadığını ortaya koymaktır. Aslında, asıl amacı, bu ülkenin bir bireyi olan doğu ve batı sentezinde büyümüss olan kendisinin de aynı zorlukları yaşadığını, toplumsal baskıların hayatını ne yönde şekillendirdiğini ve zaman ve uzamsal varlığını ortaya koymasına nasıl engel olduğunu irdelerken, kendisinin de vatanı gibi sömürülmüş olduğunu okuyucuya kanıtlamaya çalışır. 
The Impact of Female Geocriticism on Male Autocriticism: Assia Djebar's Far From Medina, Nedim Gürsel's The Daughters of Allah / C. Gümüştaş-Şen (p. 70-77)

Yazar, eserinin tarihi bölümlerinde, aslında İslamiyet'in doğduğu topraklara zihinsel yolculuk yapar. İlk bakışta jeo-eleştirel bir yorum ortaya koyar. Fakat yazar bu tarihi bölümlere eşlik eden öz yaşam öyküsel bölümler sayesinde yaşanmış tarihi anları özünü kurgulamak için ele aldığının sinyallerini verir. İslamiyet’in kendi hayatı üzerindeki etkisini tartışmaya koyarak çocukluğuna döner, din ve inanç sorgulaması yapar. Bu sorgulamanın temeline, yani eserinde ortaya koyduğu paradigmanın merkezine, kendi hayatını koyması sebebiyle, zamanı ve mekânı sabitleyemez. Dile getirdiği her coğrafi eleştiri (geocritique), öz eleştiri (autocritique) ile son bulur.

\subsection{Transgresyon, çokseslilik, göndergesellik}

Çeşitli zaman ve mekânların aynı bağlam (contexte) içinde birlikte var olması çoksesliliğe (polyphonie) yol açar. Çok seslilik ve karşılıklı söyleşim (dialogisme), çift sözcelemden (double énonciation) doğar. Ve içinde, kuşaktan kuşağa taşınacak, çift anlamlar (double sens), cevaplar ve uyaranlar bulundurur. Böylelikle, bu yeni söylem, o konuyla ilgili daha önceden yazılmış olan metinler arasına katılır. Bunlar arasında karşılıklı bir ilişki söz konusudur. Daha önceki eserlerde ele alınan zaman ve mekân(lar)ın kaleme alınmasıyla onlara birey tarafından katılan her değerin, aynı zaman ve mekân(lar) üzerine kurgulanan yeni yapıtlar üzerinde yadsınamaz bir etkisi vardır. Aynı şekilde bunun tersinin de geçerli olduğu göz ardı edilmemelidir. Bu da bizi metinlerarasılık (intertextualité) kavramına götürür.

Jeokritik, zaman-uzam bağıntısı, transgresyon ve göndergesellik (référentialité) üzerine temellendirilmiş mekân ile edebiyatın ilişkisini ortaya koymayı amaçlayan, yermerkezci, çok kuramlı, çok yönlü bakış açısına sahip, çok duyulu, çok katmanlı, metinlerarası bir edebi bakış açısıdır. Yazar, yazınında mekâna doğru hareket etmelidir, mekânı kendine çekmemelidir.

Transgresyon, bir mekândan çıkıp başka bir mekâna geçme işlemidir: mekânsızlaştırma (déterritorialisation) ve yeniden mekâna büründürme (reterritorialisation) olmak üzere iki alt zihinsel işlemi gerektirir. Assia Djebar, yazınında Cezayir ve Fransa'yı var olan coğrafyasından kopararak, onları Medine’de yeniden mekâna kavuşturmuştur. Nedim Gürsel ise; Manisa ve Fransa coğrafi mekânlarını Mekke topraklarında yeniden mekânsallaştırmıştır. Yapılan bu işlemin, bu işlemi gerçekleştiren kişi, ele alınan mekân ve zaman(lar) ve bahsi geçen kişiler üzerinde göz ardı edilemez bir etkisi söz konusudur.

Assia Djebar’ın yazınında kadın bakış açısıyla jeokritik yaptığı söylenebilirken, bu durum Nedim Gürsel için geçerli değildir. Onun, yazınında zaman ve mekân tamamıyla yazarın hizmetindedir. İslami coğrafyanın eleştirisi gibi gözüken roman, aslında bir öz eleştiridir. Jeokritik kuramının önde gelen isimlerinden olan, Bertrand Westphal, mekânın yeniden kurgulanmasında bireyin öneminin ve bireyin ona kattığı değerin öneminin altını çizer.

\section{3. (Oto)Biyografi, Tarihsel Roman ve Coğrafi Eleştiri}

Ve elbette, altı çizilmesi gereken bir diğer husus da mekânın edebi temsilinin, eserde tarihe yer vermeden yapılmasının olanaksız olduğudur. Tarihsel roman, belirli bir dönemin yeniden kurgulanmasıdır. Bu kurgulama işlemi sırasında, yazar seçtiği zaman ve uzamsal anları bir araya getirerek zincir şeklinde tarihi dokur. Yaptığı bu seçimler, hem onun hem de ele alınan dönemin ideolojisini, psikolojisini ve tarihe kattığı anlamı yansıtır.

Aslında asıl amaç, bir yandan geçmişle şimdiki zaman arasındaki bağı irdeleyerek, değişimi gözler önüne sermek, diğer yandan, geçmişte bazı şeylere müdahale ederek dönüştürmek ve geleceğe atılım yapmaktır. Zira bunu yapabileceğimiz tek yer yazıdır. Bu sebeple; Hegel'in 
Kadın Jeokritiğinin Erkek Otokritiği Üzerine Etkisi: Assia Djebar Medine’den Uzaklarda - Nedim Gürsel Allah’n Kızları / C. Gümüştaş-Şen (70-77. s.)

dile getirdiği gibi, tarihsel roman gerçek ile kurgu arasında salınımla (oscillation) ortaya konur.

“Dönüşüm, niceliğin niteliğe dönüşmesidir.” (Lukács, 1965, s 28)

Genel olarak kabul görmüş düşünceleri onaylasak da, karşı çıksak da, ünlü tarihi roman yazarı Walter Scott'ın da sözlerine katılmamak mümkün değildir.

“Geçmişi yeniden canlandırırken, tarihe bugünün geçmişi olarak bakmak gerekir” (Lukács, 1965: 56).

\subsection{Allah'zn Kzzları'nda otobiyografi, Medine'den Uzaklarda'da "kadın" biyografisi}

Nedim Gürsel’in eserinde, geçmiş (öz kurgu) ve şimdiki zaman (öz yaşam öyküsü) olmak üzere iki bölüm mevcuttur. Buna karşın; Assia Djebar'ın yazınında, içinde Cezayir'in bugününü ve kendi hayatını gizli bir şekilde barından bugünkü kadın biyografisinin geçmişi anlatılır. Bunun sonucunda, geçmişin değerlendirilmesi, günümüze ve geçmişi deneyimleyen bireyin birikimine sıkı sıkıya bağlıdır. Jeokritiğin de altını çizdiği gibi, mekânı anlamlandıran insandır. İnsan olmadan, mekânın hiçbir anlamı yoktur. Ne kadar tarafsız olunmaya çalışılsa da, tarihsel romanda bile, mutlaka bu anlamlandırmanın, öz yaşam öykümüzle ve tecrübelerimizle temas ettiği noktalar söz konusudur.

Öz yaşam öyküsü (autobiographie) ya da yaşam öyküsü (biographie) de toplumsal tarihin etkisi altında bireyin tarihinin yansıtıldığı edebi türler olması itibariyle, aslında özünde tarihsel romanlardır. Tıpkı onun gibi, geçmiş, şimdiki zaman ve gelecek arasındaki ilişkiyi ortaya koyarlar. Aslında her ikisi de hem tarihi, hem de psikolojik saptamaların olduğu çalışmalardır. Fakat bazen bu ilişkiyi ortaya koyarken yazar eserini monotonluktan kurtarmak için hayal gücünü katmak ister, bazen de gerçekleri kendi kimliğinde, bedeninde dile getirmesi güç olduğundan, bir kaçış yolu arar. İște, bu yüzden kendi hayatımızı ya da başka birinin hayatını kaleme almanın dört farklı yöntemi ortaya çıkmıştır. Bunlar, (oto)biyografi, (oto)biyografik roman, öz kurgu (autofiction) ve kurgusal (oto)biyografidir.

Otobiyografide, yazar eserin hem anlatıcısı hem de ana karakteridir. Yazar, sadece yaşanmış zaman, mekân ve kişiden bahseder. Otobiyografik roman da ise; yazar ana karakterdir. Anlatıcı ile aynı kişi olma gibi bir zorunluluğu yoktur aynı zamanda da anlatıcı ve kahramanın kimliği de tam olarak adlandırılmak ve tanımlanmak zorunda değildir, fakat yazar yaşanmış zaman ve mekândan hiçbir zaman bağını koparamaz. Eserini retorik ve poetik unsurla zenginleştirebilir. Öz kurguya gelince; yaşanmış zaman ve mekânlarını, kendi özelliklerini eserinde hayali ya da gerçek başka kahramanlar üzerine oturtarak veya onların ağzından anlatarak, yazar kendine özgürleşme imkânı yaratır. Toplumsal norm ve dogmalardan bir bakıma siyrılır. Ve son olarak kurgusal otobiyografide, yazar kendini tamamen hayali zaman ve mekâna koyar, yaşanmış zaman ve mekân(lar)la, gerçeklikle tamamen bağlarını koparır.

Daha önce de belirttiğimiz gibi, Nedim Gürsel'in yazını iki bölümden oluşur: şimdiki zamanı anlattığı otobiyografik roman ve geçmişi anlattığı tarihsel bölüm ise; öz kurgudur. Yazar, romanının öz yaşam öyküsel bölümünde çocukluğuna döner, kendi hayatını ve ailesini anlatır. Fakat bazı durumları dile getirmenin İslami değerler ve kurallar altında mümkün olmadığı yerlerde, öz kurgu bölümüne sığınır. Hem kendisi için hem de aile bireyleri için, geçmişte onların özelliklerini taşıyan hayali ya da tarihi kişiliklerden faydalanır. Bu, bir taraftan yazınını hayal gücüyle besleyerek öz yaşam öyküsü monotonluğundan kurtarırken, 
The Impact of Female Geocriticism on Male Autocriticism: Assia Djebar's Far From Medina, Nedim Gürsel's The Daughters of Allah / C. Gümüştaş-Şen (p. 70-77)

diğer taraftan da bazı durumlara öz kurgu ile müdahale ederek, var olan kimliksel sorunlarını çözmeye çalışıp, zaman ve mekânsal hâkimiyetini yeniden elde etmeye çalışır.

Assia Djebar ise; sadece öz kurgudan yararlanır. Zira sosyo-kültürel alanda giriştiği mücadelenin arkasında kendi kimliğini eritmesi gerekir. Eserinde, hemen hemen her bölümde büyük bir çoğunluğu Müslüman olan, kimileri de Hristiyan olan farklı kadınlarla karşılaşırız. Bunların her biri onun hayatından ve karakterinden bir parça taşımaktadır. Zaten, geçmişte yaşamış kadınları yeniden kurgularken tabi ki hem toplumsal tarihten hem de kendi hayatından yola çıkmıştır.

\section{Sonuç}

Sonuç olarak, daha önce kaleme alınmış olan, İslam coğrafyasına, mikro alanda, bu topraklarda ataerkil düzenin kadına biçtiği role, erkek hegemonyasına, makro alanda ise; emperyalizm ve sömürgeciliğe karşı eleştirel yaklaşım (jeokritik) getiren Medine'den Uzaklarda, daha sonra kaleme alınan Nedim Gürsel'in Allah'ın Kızları adlı yazınını, konu ve stil bakımından derinden etkilemiştir. Fakat onun yazınında ve hayal gücünde jeokritik özeleştiriye (otokritik) dönüşmüştür. Assia Djebar ise; öz kurgu yöntemiyle tarihi harmanlayarak, bulunduğu coğrafyayı eleştirmiştir.

Allah'ın Kızları, daha sonra kaleme alınmasına rağmen, tarihi açıdan, "Medine'den Uzaklarda"nın önceki cildi gibidir. Nedim Gürsel, Cahiliye döneminden başlar, Hz. Muhammed'in ölümüne kadar devam eder, Assia Djebar'in eseri ise; Nedim Gürsel'in bıraktığı yerden, Hz. Muhammed'in ölümüyle başlar ve dört halife döneminin sonuna kadar devam eder. Böylelikle, yine erkek kadının bir adım önüne geçmiştir, zira Nedim Gürsel, ataerkil düzenin erkeğe getirdiği imtiyazlara hiçbir zaman karşı çıkmaz. Aynı kaynaktan doğan, iki değerler dizisi, erkek ve kadın yaşanmışlıklarının farkıyla, tamamen farklı amaçlara hizmet eder, ve ortaya iki ayrı paradigma çıkar. Kadın yazar, coğrafi bir dönüşüm (métamorphose) hedeflerken, erkek yazar iç dönüşüme (métamorphose intime) odaklanmaktadır.

Eserlerini kaleme alırken en başta ortaya sürdükleri sorunsallarına çözüm için, Assia Djebar somut bir yol gösterir. Eserinin sonunda, "kadın”in, Hz. Ayşe'nin politik alanda söz sahibi olmasının altını çizmesiyle birlikte ataerkil düzen içinde kadının devlet yönetiminde söz sahibi olabileceğini, özgürleşebileceğini, demokrasi için bunun vazgeçilmez olduğunu ve bunun başta Cezayirli kadınlar olmak üzere, tüm Müslüman kadınlara örnek olması gerektiğini vurgular.

Nedim Gürsel ise; tam olarak bir çözüm getirememiştir, zira ne kendisi için ne de vatanı için zaman ve mekânsal varlığı tekrar ele almanın somut bir çözümünü bulamamıştır. Kitabının sonunda, içini dökmenin getirdiği rahatlamayla kar yağar, bu durum bize sorunlarından arındığını gösterir. Bu arınma gelecek için umut verir, lakin somut bir çözüm ortaya koyulmamıştır. Dolayısıyla, aynı konulara, aynı yöntemlerle değinilse de yazarın maharetiyle ortaya bambaşka iki ayrı eser çımıştır. Bu durumda da, Nedim Gürsel'in hayal gücünü ve yaratıcılı̆̆ını takdir etmek gerekir.

\section{Kaynakça}

Djebar, A. (1991). Loin de Médine. Editions Albin Michel S.A.

Gümüştaş Şen, C. (Mayss 2014). La problématique de l'espace et du temps dans l'œuvre d’Assia Djebar et Nedim Gürsel. (Assia Djebar ve Nedim Gürsel'in eserinde zaman ve mekân sorunsall). Galatasaray Üniversitesi. 
Kadın Jeokritiğinin Erkek Otokritiği Üzerine Etkisi: Assia Djebar Medine’den Uzaklarda - Nedim Gürsel Allah'ın Kızları / C. Gümüştaş-Şen (70-77. s.)

Gürsel, N. (Octobre 2009). Les Filles d'Allah. Traduit par Jean Descat. Paris: Editions du Seuil.

Lukács, G. (1965). Le Roman Historique (Tarihsel roman). Traduit par Robert Sailley. Editions Payot.

Westphal, B. (2007). La Géocritique, Réel, Fiction, Espace. Paris: Les Éditions de Minuit.

Yllancıŏ̆lu, S. S. (Aralık 2014). “Nedim Gürsel’in Yapıtlarında Dini Karakterler”. Göçebeliğin Büyüsü: Nedim Gürsel Üzerine Yazılar. Doğan Kitap. 